\title{
L'ensenyament secundari comprensiu. Contradiccions i possibilitats de les reformes educatives
}

\section{Rafael Merino Pareja ${ }^{1}$}

Universitat Autònoma de Barcelona. Facultat de Ciències de l'Educació

08193 Bellaterra (Barcelona). Spain

rafael.merino@uab.es

\section{Resum}

Aquest article pretén analitzar els elements principals que configuren l'evolució dels sistemes educatius dels països desenvolupats, fent un èmfasi especial en l'ensenyament secundari. S'hi fa un repàs al paper de les reformes educatives en aquesta evolució, especialment de les anomenades "reformes comprensives», les que tenen com a objectiu unificar el currículum i integrar la formació acadèmica i la formació professional. S'hi analitzen les virtuts d'aquestes reformes, però també les contradiccions que hi ha en la seva definició i en la seva aplicació. Finalment, s'hi apunten algunes reflexions sobre els èxits i els fracassos de les reformes comprensives a l'Estat espanyol.

Paraules clau: reforma educativa, formació acadèmica i professional i ensenyament secundari comprensiu.

Abstract. Secondary comprehensive school. Possibilities and contradictions of educational reforms

The aim of this article is to analyse the principal features of educational systems evolution in developed countries, emphasising the secondary schooling. There is an overview of educational reforms, specially the reforms called "comprehensives», that they want to unify the curricula and integrate academic and vocational education. We analyse the strength and weakness in the definition and their implementation. Finally, we add some reflections about successes and failures of comprehensive reforms in Spain.

Key words: educational reform, academic and vocational education, comprehensive secondary school.

1. Nota biogràfica: professor ajudant, doctor del Departament de Sociologia de la UAB, imparteix assignatures de l'àrea de sociologia de l'educació a la Facultat de Ciències de l'Educació de la UAB. Investigador del Grup de Recerca Educació i Treball, col-lectiu que treballa en les àrees de la relació entre formació i ocupació, formació professional, avaluació de polítiques públiques, transició dels joves a la vida activa. L'article és el desenvolupament d'una part del marc teòric elaborat per a la tesi doctoral, llegida el 10 de juliol de 2002, dirigida pel doctor Jordi Planas, amb el títol De la contrareforma de la formació professional de la $L G E$ a la contrareforma de la LOGSE. Itineraris i cicles de formació professional després de l'ensenyament secundari comprensiu. 


\section{Sumari}

\section{Introducció}

2. El context de les reformes

comprensives

3. L’aplicació de reformes comprensives a Europa
4. Propostes d'unificació de la formació acadèmica i la formació professional 5. Reflexions finals per al cas espanyol Bibliografia

\section{Introducció}

Els sistemes educatius són en el centre de molts debats polítics i socials, però l'ensenyament secundari ha estat especialment objecte de nombroses reformes. El debat fonamental se situa en el grau d'unificació o de diversificació d'aquesta etapa, i això té traduccions en el currículum, en l'organització dels centres, en el professorat i en els recursos que es destinen a les reformes. Però, més enllà d'aquestes qüestions, també hi ha una discussió teòrica (i ideològica) sobre el sentit i les possibilitats d'unificació de l'ensenyament secundari. En aquest article, fem un repàs als diferents intents que s'han realitzat d'introduir reformes comprensives, és a dir, reformes d'unificació o de tronc comú en l'etapa de secundària, si més no en la secundària inferior, fins als setze anys, des d'una perspectiva sociològica. Així, hi analitzem el context sociohistòric en el qual s'impulsen les reformes educatives anomenades "comprensives", hi analitzem les propostes de diferents autors per reeixir en la unificació de la via acadèmica amb la via professional i hi expliquem alguns efectes no volguts o perversos en l'aplicació d'aquestes reformes en alguns països europeus.

Hi dediquem un últim apartat a descriure el que ha passat a l'Estat espanyol amb l'aplicació de la LGE i de la LOGSE. El cas espanyol en els darrers anys ha estat especialment paradigmàtic en l'ús i l'abús de les reformes educatives com a instrument de política docent a curt termini. Quan s'acabava d'aplicar la LOGSE, el govern del PP tornava a canviar les regles de joc amb la LOCE, introduint itineraris a la secundària obligatòria i rebaixant, de facto, el tronc comú als quinze anys amb la introducció dels programes d'iniciació professional. Davant del més que probable canvi legislatiu amb el nou govern socialista $^{2}$, recordar alguns esdeveniments que van succeir amb l'aplicació de la LGE i la LOGSE pot ser útil per adonar-se de les limitacions que tenen les disposicions legals per transformar la realitat.

\section{El context de les reformes comprensives}

El tema clau en l'evolució dels diferents sistemes educatius europeus (i occidentals en un sentit més ampli) ha estat la comprensivitat en l'ensenyament

2. Escric aquests ratlles a finals de març de 2004, quan encara no s'ha format el nou govern socialista després de les eleccions del 14-M. 
secundari, objectiu de bona part de les reformes educatives. El significat de la reforma ha anat variant al llarg del temps, però ha tingut com a objectiu la millora social a través de l'educació i a través de diversos discursos: democratització de l'ensenyament, disminució de desigualtats, ajustament a noves necessitats socials i econòmiques, etc.

Cal dir que aquest objectiu no està exempt de contradiccions, com s'han encarregat de demostrar diferents autors. Des de la visió marxista clàssica, Bowles i Gintis ja afirmaven que «el fracaso de las reformas educativas progresistas se desprende de la naturaleza contradictoria de los objetivos de la función integradora, la igualitaria y la desarrollista en una sociedad con una vida económica regida por las instituciones del capitalismo empresarial» (1985, p. 66). La pretensió de canviar la societat a través de l'escola, més que voluntarista, és ingènua. El mateix Boudon diu: «El único factor capaz de reducir las desigualdades ante la enseñanza en una perspectiva no utópica reside en la reducción de las desigualdades económicas y sociales» (Boudon, 1983, p. 193, cursiva a l'original) ${ }^{3}$.

Per a Ball (1995), aquest és el rerefons de les polèmiques o la tensió, com ell diu, entre la visió humanista i la visió tecnològica de l'ensenyament ${ }^{4}$. Les reformes que tendeixen a fer èmfasi en la funció de preparació per a la vida activa reben crítiques de sectors diversos (professorat ancorat en la visió academicista, una fracció de les classes dirigents), perquè devaluen l'escola i van en perjudici de la formació cultural de la ciutadania o, més ben dit, dels grups socials més presents a l'escola (postobligatòria). D'aquí vindran pressions per desvincular la formació professionalitzadora del tronc comú acadèmic i externalitzar-la del sistema (si més no, la formació professional de baixa qualificació, com veurem més endavant).

Una altra qüestió referent a les reformes educatives, tractada més sovint des de la ciència política, fa referència al policy making process, és a dir, les con-

3. No podem oblidar que també existeix un discurs conservador en contra no de la reforma educativa, sinó de la reforma social a partir de l'acció pública o estatal, per dues raons: perquè l'Estat no està legitimat per interferir en la vida privada $i$ "natural» de l'individu (com van ser el darwinisme social i el pensament conservador del segle XIX —Riesman, 1981—) o perquè la seva acció genera més efectes perversos que no pas beneficis (Crozier, 1984).

4. Cal fer notar que, des d'una posició crítica i postestructural, aquest autor analitza les polítiques educatives conservadores des de finals dels anys setanta al Regne Unit, $\mathrm{i}$ una de les tendències (no pas l'única dintre del conservadorisme) ha estat refer el currículum en termes humanistes "clàssics» (exaltació de l'anglès com a llengua de comunicació, referència constant a la història imperial, etc.). No entraré en el tema del currículum de la formació general i la formació professional, però és evident que existeix una correlació clara amb l'anomenat "problema de les humanitats a Espanya». La visió tecnològica també té els seus defensors i detractors. En un llibre recent, Postman, reconegut exponent dels corrents més «tecnòfobs», criticava l'opció del govern nord-americà pel «vocacionalisme» com a nova educació del segle XXI, si precisament «la formació de persones indagadores, obertes, curioses i adaptables (allò que necessita el nou paradigma productiu) no té res a veure amb la preparació de la vocació i tot el que està relacionat amb els estudis científics i humanístics» (Postman, 2000). 
dicions en les quals una reforma es gesta, s'elabora i s'aplica. No és un procés ni mecànic ni lineal, hi ha canvis significatius segons la pressió i la negociació d'interessos, l'eficàcia de les lleis i l'estructura politicoadministrativa. Segons Husén (citat per Pedró i altres, 1998), hi ha sis elements clau perquè una reforma educativa tingui èxit:

a) Que vagi acompanyada d'una reforma social. Com ja s'ha dit abans, una reforma de l'escola per si mateixa no pot garantir objectius tan ambiciosos com la disminució de les desigualtats. Aquest també és el terreny de les polítiques econòmiques i socials.

b) Que sigui viscuda com a necessitat des dels centres escolars. La dimensió local també és important. Això vol dir que les reformes centralitzades han de partir de la vivència compartida de centres escolars. Com diu Husén: «Los destinatarios de las reformas son los centros escolares, y si en su seno no se ve la necesidad de una reforma, ¿quién la llevará a cabo?» (op. cit., p. 63).

c) Les millors reformes són les més lentes, compassades als temps de les modificacions socials. Si no hi ha un període de canvis sobtats globalment (per exemple, en èpoques revolucionàries), el millor és preveure'n una aplicació lenta i gradual, amb resistències al canvi, inèrcies creades i grups opositors. Cal tenir en compte que Husén parteix de l'experiència sueca, que va durar trenta anys des de la seva gestació fins a la seva generalització. Les grans reformes de «moment» que prometen molt en poc temps acostumen a tenir garantit el fracàs a causa de les inèrcies culturals o les pràctiques de la mateixa administració educativa (Planas, Tatjer, 1982).

d) Que hi hagi un ampli consens entre els afectats, això porta a considerar com es construeix aquest consens, és a dir, com es creen mecanismes de participació no nominals, sinó efectius i reals a totes les fases de la reforma. En aquest sentit, és fonamental la participació i la implicació del professorat, que serà qui, en definitiva, aplicarà les reformes. Si el professorat està desinformat, poc motivat i sobretot es veu amenaçat en el seu estatus o les seves condicions laborals, difícilment col-laborarà amb l'Administració en l'aplicació de les reformes educatives ${ }^{5}$. El consens ha de partir del joc de poder entre els diferents agents socials, amb interessos divergents i a vegades contraris.

e) S'han de preveure les resistències al canvi amb estratègies que incloguin una bona política d'informació i difusió. Les resistències al canvi es poden traduir en atacs a les reformes o en l'elaboració de discursos i de pràctiques deslegitimadores de les innovacions organitzatives o pedagògiques que es volen aplicar.

f) Finalment, cal crear mecanismes de control i avaluació de totes les fases de la reforma que generin informació veraç sobre el grau d'acceptació d'aquella, per poder-hi introduir els canvis pertinents.

5. Com és el cas del professorat de BUP, amenaçat per la unificació de la secundària en la reforma espanyola i, per tant, contrari a aplicar-la (Masjuan, 1994). 
Tedesco (1994) fa èmfasi, d'entre aquests sis elements, en la necessitat de consens (en paraules seves, passar de polítiques governamentals a polítiques d'estat) $i$ en el plantejament a llarg termini. Sovint, les esperances posades en grans reformes que prometen canvis radicals en poc temps generen més frustracions i efectes perversos que acaben imposant una visió negativa o pessimista sobre les possibilitats del sistema educatiu per canviar (p. 77).

Malgrat les contradiccions que hem esmentat, l'aplicació de les reformes comprensives s'ha justificat amb l'objectiu de disminuir les desigualtats socials. Els arguments a favor de la reforma comprensiva es van estendre pels diferents organismes internacionals i són resumits per Fernández Enguita (1990):

a) Evitar els efectes discriminatoris de la selecció precoç segons l'origen social per augmentar la igualtat d'oportunitats escolars.

b) Aprofitar millor la capacitat de detectar l'alumnat més capaç i contribuir al progrés de la nació (en un context de necessitat de formar capital humà).

c) Fer arrelar la igualtat d'oportunitats des d'un punt de vista meritocràtic, és a dir, transformant els conflictes de classe en competència interindividual.

d) Reforçar els estudis secundaris professionalitzadors de segon cicle o superiors no universitaris i corregir la tendència a l'alça de la matriculació en la via acadèmica cap a la universitat.

Aquests efectes benèfics sobre la reducció de la desigualtat social no sempre generen un consens entre agents socials i entre investigadors. Si bé les vies separades tendeixen a reproduir la desigualtat social, la unificació presentaria problemes per als adolescents que no volen estudiar, que no estan motivats o capacitats per continuar estudiant (Arum, Shavit, 1995). L'opció de la FP per a aquest alumnat representa, per a sociòlegs com ara Collins, un senyal negatiu que indica un nivell baix $\mathrm{i}$ actituds negatives envers l'aprenentatge ${ }^{6}$, però des de la perspectiva de la teoria del capital humà, s'ha intentat demostrar, amb estudis empírics, que, malgrat tot, la FP dóna més probabilitats de trobar feina i d'evitar l'exclusió laboral que si no es tenen aquests estudis, com també dóna més probabilitats de continuar estudis tècnics superiors (Arum, Shavit, 1995).

El repte més important i de més consens és que la selecció dels individus no depengui de l'origen social, en el context de massificació de l'ensenyament. Aquesta massificació de l'ensenyament secundari fa perdre el caràcter elitista que històricament ha tingut i fa entrar en crisi (o, més ben dit, hi ha una pèr-

6. Segons aquest autor, «una de las razones principales del fracaso de las enseñanzas profesionales es probablemente que las escuelas [...] donde éstas se imparten son conocidas como lugares a donde son enviados los jóvenes conflictivos para eliminarlos de las escuelas regulares. El estado de guerra entre profesores y estudiantes en una escuela secundaria regular es considerado apacible comparado con la violencia de tipo gansteril —a menudo con connotaciones raciales - que se sabe que se produce en las escuelas técnicas. Aun si un estudiante en estas materias llega a aprender técnicas útiles, su asistencia a una escuela profesional es muy probable que sea tomada por su "perspicaz" empleador como un signo de mal carácter» (Collins, 1989, p. 23). 
dua de consens sobre) els objectius d'aquesta etapa. És com si, en la mesura que s'estén l'escolarització, els sistemes educatius es diversifiquessin internament. El creixement de les taxes d'escolarització dels adolescents planteja forts dilemes i paradoxes. En primer lloc, si la via acadèmica creix en efectius, de seguida apareixen les veus crítiques sobre la baixada de nivell; si el creixement és derivat cap a les vies tecnicoprofessionals, apareix el perill de la sobreeducació (Halls, 1994, p. 27).

Un altre dels dilemes de fons és la pugna entre l'excel-lència i l'equitat, i això depèn del model polític i del valor que tingui la igualtat. Així, un model comprensiu tindrà com a objectiu evitar l'exclusió social amb una educació comuna, i un model selectiu pretendrà oferir a tots els ciutadans les millors possibilitats segons la seva funció social, dintre d'un sistema meritocràtic (Tiana, 1988). En el fons, hi ha una discussió ideològica. Per això podem parlar de reformes en pro de la comprensivitat en èpoques de més suport a les polítiques igualitaristes i de contrareformes en contextos de qüestionament de l'igualitarisme i de recerca d'eficàcia i competitivitat, de privatització i mercantilització (Benadusi, citat a Rescalli, 1995).

\section{L'aplicació de reformes comprensives a Europa}

No hi ha una evolució homogènia als diferents països europeus, però, fins a la dècada de 1960, la separació de la formació professional de l'ensenyament general (el que s'havia definit com a FP segregada) era un tret comú a tots els països europeus (Gregoire, 1967). A més, la via professional era una segona opció per la qual només es decantaven els fracassats o desinteressats per la via acadèmica general. Unes altres característiques comunes eren l'extrema generalització (dels continguts) i l'escassa implantació en termes quantitatius (op. cit.). Però l'augment de les taxes d'escolarització al llarg dels anys cinquanta i seixanta, en la construcció de l'anomenada «escola de masses», va fer canviar radicalment el panorama educatiu, especialment pel que fa a la secundària i a l'ensenyament professional:

- D'una banda, una educació prolongada no pot ser eficaç si no està orientada cap a la preparació a la vida activa;

- d'altra banda, una educació que s'adreça al conjunt de la joventut no pot ser concebuda només com a via d'accés a l'ensenyament;

— finalment, una educació obligatòria de llarga durada facilita una especialització professional de curta durada (Gregoire, 1967, p. 73, en francès a l'original).

En aquest llibre (que era un informe per a l'OCDE), ja s'apuntava, l'any 1967, que l'escola del futur havia de ser una escola única, amb una secundària obligatòria amb els primers anys indiferenciats i una segona etapa d'especialització, però amb vies del mateix estatus, i que la selecció s'havia de fer sense biaixos per classe social o d'altres variables que no fossin estrictament acadèmiques i meritocràtiques. En definitiva, s'apuntava a la construcció d'una esco- 
la comprensiva. A més, uns altres estudis destacaven que la formació professional és molt més rendible econòmicament quan la població ja té un bon nivell d'ensenyament general (Mingat, Tan, 1988) i molt més equitatiu (McMahon, 1988; Bowman, 1988).

Podem dir que les primeres reformes educatives comprensives s'introdueixen en les reformes dels anys seixanta i setanta (com és el cas de Suècia i el Regne Unit, i l'intent d'Alemanya) amb l'objectiu de retardar la selecció de l'alumnat, amb el benentès que això es feia amb el propòsit de limitar la desigualtat social que produïa la separació en edats precoces entre itineraris acadèmics i professionals. S'esperava que allargar l'escolaritat augmentaria la igualtat d'oportunitats i que l'opció entre diferents estudis (acadèmics clàssics, acadèmics moderns, tècnics) i sortir al mercat de treball dependria més de l'experiència escolar i de la vàlua personal i menys de l'origen familiar.

El cas del Regne Unit és el més significatiu. Als anys cinquanta, s'hi instaurà la comprehensive school en un context de governs laboristes, que tenia per lema grammar school per a tothom, i va rebre el suport de les classes mitjanes i d'un segment important de la classe baixa amb voluntat de mobilitat social i diferenciació (Rescalli, 1995). A més, l'ampliació del tronc comú de la secundària plantejà reptes pedagògics importants, perquè hi havia un augment de la diversitat $\mathrm{i}$ un creixement d'alumnat amb actituds antiescola o amb interessos allunyats de l'academicisme tradicional de la institució docent. No s'ha d'oblidar que l'escola comprensiva no substitueix ni les grammar school ni les modern school, sinó que hi coexisteix, la qual cosa ens dóna una idea del grau d'èxit de la seva implantació. A més, fins i tot a les escoles comprensives, hi havia un cert grau de streaming, és a dir, agrupació d'alumnes segons el nivell de rendiment en un percentatge del currículum comú (Fernández Enguita, 1987; Garcia, 2001) i, per més que busquessin integrar els diferents grups socials, els centres de secundària no podien escapar de «l'ecologia social», és a dir, de les clienteles que tenien per territori (Fernández Enguita, 1987).

És obvi que aquestes reformes s'implantaren amb el suport de grups socials i polítics en un context d'ideologia igualitària i de presència forta en l'agenda pública de partits socialdemòcrates i agents socials progressistes. A partir de mitjan anys setanta, començà un corrent fortíssim que qüestionava tant els objectius com els sistemes de l'ensenyament comprensiu, en un marc de devaluació de les polítiques igualitaristes i de realçament de les polítiques d'excel-lència, selecció dels millors i recerca de l'eficàcia, marc que, amb algunes variacions, és el que ha arribat als nostres dies. De nou el cas britànic és paradigmàtic. El model entra en crisi a mitjan anys setanta ${ }^{7}$, i amb els conservadors als vuitanta s'inicià una contrareforma en tota regla, amb una crítica als

7. És interessant la tesi de Rescalli, que afirma que la contrareforma és iniciada amb els laboristes l'any 1976, amb un discurs del primer ministre Callaghan que provocà un great debate sobre la mediocritat de les escoles britàniques. Això fa pensar que la dinàmica reforma $\mathrm{i}$ contrareforma és més profunda que el simple canvi de govern en un país, i respon a situacions més profundes i estructurals. 
«pobres» resultats en termes de rendiment $\mathrm{i}$ amb una introducció del discurs de la competitivitat del país, que necessitava tenir un sistema més selectiu i una formació professional més d'acord amb les necessitats del sistema productiu (origen del conegut NVQ). Es tractava de posar ordre al conjunt del sistema, molt diversificat i fragmentat, sobretot en la formació professional ${ }^{8}$. També cal tenir en compte que sectors significatius de les classes mitjanes van posar moltes resistències a convertir les selectives grammar schools en comprehensive schools, o van utilitzar com a estratègia de distinció afegir a aquestes el sixth form, que prepara els A-Level per a l'accés a la universitat (Kerckhoff i altres, 1997).

Malgrat tot, a partir dels anys noranta començà un debat fort arran de la publicació d'un llibre, A British Baccalaureate, de Finegold, que posa sobre la taula la qüestió de la unificació de l'ensenyament postobligatori (franja 16-19 anys). Investigadors anglesos, com ara Young i Raffe, defensen aquesta unificació com la millor manera de desenvolupar la learning society, i argumenten que la separació entre treball manual i treball intel.lectual serà cada cop més inoperant en el mercat de treball amb les noves formes de producció i d'organització laboral (Young i altres., 1997). Així, el British Baccalaureate tindria com a objectiu «crear un sistema educatiu amb una elevada participació i una selecció tardana, que integrés l'educació acadèmica i la professional. En condicions ideals, aquesta educació s'oferiria a través d'una xarxa d'escoles superiors, però a curt termini els canvis s'han de centrar en un nou currículum i un sistema d'avaluació per al sector» (Green, 1991, p. 13, en anglès a l'original). El debat no ha arribat a concretar-se en normes legislatives, però sembla clar que, cada cop més, les decisions dels joves van en la línia d'acumular titulacions per millorar l'accés al mercat de treball i que la FP es va convertint cada cop més en una via per accedir al nivell superior que no pas per sortir al mercat de treball amb una qualificació massa especialitzada (Green i altres, 2001).

En qualsevol cas, el nou context és procliu a desmuntar per diferents bandes la secundària comprensiva o a reforçar les vies segregades en els països que sempre n'havien tingut. El cas d'Alemanya és molt significatiu, ja que és l'exemple típic d'un sistema radicalment segregat en la franja 10-16 anys entre la formació acadèmica elitista (Gymnasium) i una formació més pràctica (Realschule i Hauptschule), que desemboca en la coneguda formació dual. Als anys setanta, s'hi va intentar fer una reforma comprensiva amb la creació de la Gesamtschule, però només va arribar al 5\% de cada generació (Rescalli, 1995). Encara que l'accés al sistema dual no té exigències de titulació prèvia, aquest varia

8. Pel que fa al cas de Suècia, l'any 1992 s'hi introdueix una altra reforma que organitza l'ensenyament secundari superior en grans àrees professionals amb una gran opcionalitat per part de l'alumnat, en un context polític diferent, en el qual es comença a qüestionar si tothom ha de rebre una formació que doni accés a una qualificació àmplia i profunda. De fet, aquest fenomen reflecteix la paradoxa de l'ensenyament secundari massificat, que provoca, en un percentatge significatiu d'alumnes, el rebuig de les assignatures instrumentals, considerades avorrides, i que troben a faltar el contacte amb els oficis manuals, que és de fet el que marca l'horitzó de classe. També es comença a qüestionar que tots els estudiants de FP hagin de fer pràctiques en empreses (Gustafsson, Madsén, 1999). 
segons la branca d'activitat. Per exemple, a la banca i a la indústria dominen els certificats de Realschule, i als oficis artesans són majoria els que surten de la Hauptschule (Llorent i altres, 1999, p. 102-103) ${ }^{9}$. Els darrers anys, però, l'arrelat sistema dual comença a entrar en crisi per la massificació dels estudis acadèmics, que a més es comencen a utilitzar no només per anar a la universitat, sinó també a la FP superior. D’altra banda, la Hauptschule veu reduït el seu pes i, a més, amb una explosiva concentració de població immigrant, que amb el certificat d'estudis quan entra al sistema d'aprenentatge té problemes per trobar empreses on pugui fer la formació pràctica (Born, 1996). Un fenomen semblant ha passat a Dinamarca, on la manca d'empreses que oferien pràctiques per a alumnat de FP va portar el govern a crear les school-based practical training program l'any 1990 (Osterlund, 1999, p. 173).

El cas de França és peculiar. Segons Rescalli, s'hi ha donat una curiosa coincidència entre un país fortament centralitzat i la incapacitat de dur a terme reformes globals, que ha fet reformes parcials i de caràcter acumulatiu que han provocat l'aparició d'una franja d'ensenyament secundari molt complexa i amb coincidències entre centres i titulacions. En qualsevol cas, s'hi va unificar el secundari inferior (11-15 anys) l'any 1975, però s'hi va introduir un currículum tècnic l'any 1985, fet que va trencar amb el concepte de comprensivitat.

Com s'ha vist, no és facil establir un model «europeu», ja que les tradicions de cada país són prou fortes, tan fortes que fins ara ha estat pràcticament impossible establir correspondències entre els diferents títols per afavorir la lliure circulació de persones a la Unió Europea, cosa que referma la distància entre el discurs i la retòrica oficial de la Unió Europea i les possibilitats reals d'una convergència en matèria educativa (Green i altres, 2001). En qualsevol cas, sí que es pot veure aquesta tendència global de fases successives d'èxit de les polítiques comprensives i de qüestionament o fracàs relatiu d'aquestes polítiques.

\section{Propostes d'unificació de la formació acadèmica i la formació professional}

Una alternativa al tronc comú en l'ensenyament postobligatori és el manteniment de les vies acadèmica i professional però amb punts de connexió (linked systems, a Jackson, 1999). De fet, la tendència dels darrers anys a diferents països europeus va en aquesta línia: la diversificació dels dispositius de formació professional (amb la consegüent pèrdua de coherència del sistema) en connexió amb l'ensenyament secundari superior o fins i tot amb la universitat. També s'està plantejant (p.e., al Regne Unit) el desenvolupament de combinacions entre mòduls formatius generals, professionals i específics (Tessaring, 1999). Malgrat tot, existeixen encara molts obstacles per passar de la formació professional (sobretot de baix nivell) a l'ensenyament general, i això condemna d'alguna manera la FP a restar en un segon pla respecte a la seva valoració

9. De manera similar, la distribució a Espanya de graduats i certificats escolars variava segons la branca professional, i segurament també variarà en funció del cicle formatiu. 
social. Per això, un informe del CEDEFOP ${ }^{10}$ afirmava: «Dado que la atracción de la formación profesional depende en gran medida de su estatus social y de su posición dentro del mercado de trabajo en términos de desempleo, salarios, oportunidades profesionales y posición profesional, los decisores políticos debieran esforzarse en todo lo posible para garantizar un valor equivalente entre los itinerarios educativos de carácter más general y la formación práctica» (Tessaring, 1999, p. 22).

Les tradicions de cada sistema educatiu respecte a l'existència d'una formació professional té incidència en moments d'expansió educativa. En aquells països amb una tradició forta de FP, i a més connectada amb el món laboral, aquesta ha pogut absorbir l'augment de la demanda d'educació (vinculada a la demanda creixent de treballadors qualificats). En canvi, en aquells països com ara l'Estat espanyol, amb una FP que no és un referent per al mercat de treball, la demanda creixent d'educació ha fet pressió sobre la formació acadèmica, la qual cosa ha acabat fent augmentar la petició de places universitàries. Això explicaria per què els països del sud d'Europa han tingut un creixement de la població universitària tan important al llarg de les darreres dècades (Müller i altres, 1999). En aquest sentit, l'expansió de la FP ha estat vista per alguns autors com una manera d'evitar l'accés de les classes populars a l'ensenyament general i superior (McMahon, 1988; Grubb, 1985).

No es tracta de fer comparacions per veure quin és el «millor» sistema, perquè aquest no ha estat mai l'objectiu de l'educació comparada (García Garrido, 1986), sinó de tenir en compte el marc «societal» dels sistemes educatius en general i de la formació professional en particular. Malgrat aquesta dimensió «societal», en el context europeu alguns autors parlen d'una certa convergència «d'equivalències funcionals» (Fourcade, 2000, p. 9) en dos tipus de cicles de FP: un de curt d'accés a la vida activa i un de llarg d'accés als estudis universitaris curts, tot això en un context d'unificació del tronc comú a la secundària inferior i del retard de la separació de les vies acadèmica i professional dels deu anys als quinze. De fet, l'augment de les taxes d'escolarització en la secundària superior ha estat gràcies a la FP de cicle llarg (llevat del Regne Unit), que ha anat desplaçant els cicles curts per a les generacions nascudes els anys vuitanta, encara que a l'Estat espanyol aquest procés ha estat més feble (Fourcade, 2000, p. 14).

Un dels esforços teòrics més importants en la línia d'unificació de la secundària postobligatòria és el que s'està realitzant a l'Institut d'Educació de la Universitat de Londres, l'Unified Learning Project, del Post-16 Education Centre. Els principals investigadors proposen realitzar una unificació (no uniformització) de l'ensenyament postobligatori, d'alguna manera recuperant l'esperit de la comprensivitat dels anys seixanta, encara que sense el reconeixement social que va tenir. Alguns dels principals investigadors parteixen de la idea que els canvis socioeconòmics a l'Europa dels noranta juguen a favor d'a-

10. European Centre for the Development of Vocational Training. 
questa unificació (Raffe i altres, 1997), ja que la transformació de la divisió social del treball fa que sigui menys necessària l'especialització (i menys encara per als adolescents) i, d'altra banda, l'augment de la individualització de les societats postmodernes i la progressiva polarització social està augmentant la pressió de les famílies cap a la via acadèmica ${ }^{11}$, amb l'augment de probabilitats d'exclusió social per als fracassats d'aquesta via.

Passar d'un tracked system a un unified system no és facil i dependrà de cada país, però es poden establir uns objectius generals comuns (Raffe, 1997, p. 13):

- Incrementar l'atractiu de les oportunitats per als estudiants de baix rendiment, amb l'objectiu de reduir l'abandó i l'exclusió, i desincentivar la «deriva acadèmica» cap a la formació de més estatus;

- promoure una valoració semblant de la formació professional i de l'acadèmica, com a mitjà per aconseguir el primer objectiu, i millorar l'oferta de cursos per a l'adquisició, per part dels joves, de les capacitats generals i tècniques;

- modernitzar el currículum per promocionar el desenvolupament de nous tipus d'habilitats i coneixements, necessaris per a la futura inserció laboral i per a la vida adulta;

- incrementar la flexibilitat, per permetre més oportunitats, evitar carrerons sense sortida i tenir més en compte les necessitats dels estudiants i dels empleadors, $\mathrm{i}$

- millorar la coherència, la coordinació i la transparència del sistema (negreta a l'original, en anglès a l'original).

Amb tot, la unificació serà més o menys facil en funció dels sistemes existents, però la pressió per al canvi és present a tots els països, si més no per acostar els sistemes més segregats als linked systems, encara que no s'arribi a la unificació de les vies acadèmiques i professionals (op. cit.) ${ }^{12}$. No falten veus crítiques

11. En el cas britànic, l'augment de la matrícula en els $A$-level ha crescut de manera sostinguda des de l'any 1986, en què representava un 15\% de la cohort, fins a l'any 1994, que ja representa la quarta part dels joves d'entre setze i divuit anys (Spours, 1996b).

12. És el cas de l'intent d'unificació d'Anglaterra amb les GNVQ, encara que no ha acabat de funcionar com a alternativa a la via acadèmica de prestigi dels $A$-Level (Young i altres, 1995), ja que és difícil mantenir un estatus elevat i al mateix temps donar una qualificació professional. Si hi ha un estatus elevat (per exemple, amb la possibilitat d'accedir a l'ensenyament superior), una part important de l'alumnat no veurà la via professional de prestigi com a terminal, sinó com a via cap a la universitat o als estudis superiors (és el cas del $60 \%$ de l'alumnat dels Advanced GNVQ i el 40\% de l'Intermediate GNVQ). D'altra banda, des del món empresarial i els centres de formació professional s'ha criticat els GNVQ perquè no donava prou formació tècnica. Finalment, el GNVQ queda com una via acadèmica de menys estatus (Spours, 1996a), però amb més claredat d'objectius i expectatives respecte al futur que la resta de títols professionals massa dispersos, encara que el risc de fracàs sigui més gran: «Malgrat la popularitat inicial dels GNVQ, és massa aviat per valorar la seva eficàcia; molts estudiants continuen en risc de fracàs en les restrictives vies acadèmiques perquè les recompenses d'aquestes vies estan definides d'una manera molt clara» (Richardson i altres, 1996, p. 17). 
d'aquesta visió, en dues direccions. La primera és que és difícil unificar criteris que tenen naturalesa diferent, com ara la formació acadèmica i la professional, i en definitiva les reformes que apunten als linked systems no deixen d'afectar una minoria d'estudiants (Leclerq, 1994). La segona crítica parteix de la idea que el desenvolupament d'un currículum comú (core curriculum) fa més invisibles els antagonismes i els conflictes socials (Avis, 1992).

Fora del context europeu, també hi ha hagut aquesta convergència de generalització de l'ensenyament secundari inferior i el retard en la separació entre les vies acadèmiques i professionals. Alguns països han optat per incorporar formació "vocacional» en el currículum de secundària, sobretot quan el 80\% de la promoció està escolaritzada, com en el cas d'Austràlia (Sweet, 1999, p. 83). Malgrat la presència d'aquesta opcionalitat de tipus professional, l'opció de continuació d'estudis a la universitat és majoritària. Això vol dir que l'augment de la secundària superior porta com a conseqüència una pressió més gran cap a la universitat, encara que s'incorpori dintre del currículum formació pensada per a la transició a la vida activa.

El cas del Japó és singular. Gairebé obligat pels aliats vencedors a unificar l'ensenyament secundari superior després de la Segona Guerra Mundial i establir un programa comprensiu ( $\mathrm{amb}$ assignatures generals i professionals en centres integrats per territori), passa una etapa de progressiva especialització durant els anys cinquanta i seixanta cap a la via acadèmica o la via professional. Els anys setanta veuen augmentar aquesta segregació amb un increment de la competició entre les high schools, que queden classificades de la manera següent: centres de secundària acadèmica amb accés a la universitat de prestigi elevat, centres de formació professional que asseguren ocupació estable (a través del sistema japonès de vincular centres a empreses) i centres d'estatus baix, sobretot en zones desfavorides (Inui, Hosogane, 1995). Aquest sistema tan segregat per centres i per les vies acadèmica i professional (amb una escolarització en l'ensenyament secundari superior que arriba al $90 \%$ de la promoció) ha portat a una discussió als anys noranta sobre la reforma de l'ensenyament secundari, per recuperar un cert grau de comprensivitat i disminuir la tensió que provoca la competició entre les escoles, i per la pressió de continuar estudis acadèmics (el 30\% d'alumnes de FP voldrien seguir la via acadèmica, però aquesta és molt selectiva), per això s'ha fet una reforma comprensiva (integrated high school) que encara és massa aviat per avaluar-la (Kariya, 1999, p. 305).

La unificació radical entre el treball manual i l'intel-lectual (a l'escola i, com a efecte, a la societat), vell somni de pedagogs reformistes com ara Dewey o Freinet, no ha tingut èxit ni als països socialistes o amb polítiques socialdemòcrates amb orientacions "soviètiques», com ara el cas de Malta als anys setanta (Sultana, 1995), l'Índia de Gandhi o la Xina de Mao (Zachariah, 1988). A part de les raons específiques (en podem dir "societals») del fracàs de les reformes educatives radicals en aquests països i en d'altres (Canadà el 1913, segons aquest darrer autor), hi ha unes raons més estructurals o de fons que fan que les diferències de classe no es puguin eradicar facilment i a través de reformes educatives. D’aquestes raons, n’hi ha que són internes al sistema edu- 
catiu: problemes burocràtics, problemes pedagògics (el treball manual realitzat en una escola no ha de ser necessàriament més atractiu o més motivador que les assignatures tradicionals) o problemes financers. Però també hi ha raons externes de tipus sociològic que són molt importants. Zachariah ho resumeix en una pregunta: com es pot fer rellevant el treball manual a l'escola a les classes baixes si aquestes saben que les oportunitats socials depenen dels oficis no manuals? (op. cit., p. 220-221). És a dir, quan la divisió social del treball és complexa i l'educació queda fora de l'àmbit socialitzador dels grups primaris i particulars, i passa a institucions formalitzades i universalistes d'ensenyament, és molt difícil unificar el treball manual i intel-lectual. Buscar un currículum que equilibri aquest binomi, en el fons oculta un desig de tornar a sistemes socials de petites comunitats no mercantilitzades (Zachariah, 1988, p. 222) i de divisió simple del treball ${ }^{13}$. Però la il.lusió del canvi social a partir de l'escola es manté perquè sembla molt més facil canviar l'escola que no pas el medi socioeconòmic i el mercat de treball, i això fa que s'esperi de l'escola més del que pot oferir en termes de mobilitat social o de preparació professional (Bowman, 1988). Però les barreres de l'igualitarisme són molt importants: quan un nivell educatiu integra les diferències (de classe, ètniques) es torna més irrellevant per accedir a les millors ocupacions, i la lluita per a la integració es desplaça al nivell següent (Grubb, 1985, p. 542). Augmentar l'igualitarisme en l'accés a l'educació implicaria restringir-hi l'accés als fills de les classes altes, cosa que políticament és inviable. L'igualitarisme sempre acaba promocionant l'escolarització de les classes baixes, però provoca un procés inflacionari, ja que les classes mitjanes i altes encara estudiaran més anys per mantenir les seves posicions socials (op. cit., p. 543). En un estudi més recent ${ }^{14}$, s'arribava a una conclusió similar, en el sentit que un augment de les taxes d'escolarització no implicava més igualtat d'oportunitats, ans al contrari, era una estratègia dels grups socials dominants precisament perquè persistissin les desigualtats socials.

\section{Reflexions finals per al cas espanyol}

Les possibilitats i contradiccions de les reformes comprensives que hem analitzat han tingut lloc amb molta claredat als dos intents de reformes comprensives de les últimes dècades, la LGE (1970) i la LOGSE (1990). Amb la LGE es va dissenyar una FP integrada, com a cicles després de cada etapa educativa. La FP1 després de l'ensenyament bàsic, la FP2 després del batxillerat i la FP3 després del primer cicle universitari. Però l'aplicació del decret de 1974 va produir una

13. Que és precisament l'objectiu d'algunes comunitats que rebutgen el sistema educatiu i el sistema social i formen petits nuclis aillats amb la voluntat de tornar a una divisió social del treball molt simple. O també de les propostes utòpiques d'integració entre el treball manual i el treball intel-lectual, a l'estil de Comenio o del socialisme utòpic (Manacorda, 1985).

14. Blossfeld, SHAVIT (1993). Persistent Inequality Changing Educational Attainment in Thirteen Countries, Westwiew/San Francisco/Oxford, citat a Tessaring, 1999. 
autèntica contrareforma, ja que va permetre la connexió de la FP1 amb la FP2 i obligava els alumnes que havien fracassat a l'EGB a matricular-se a la formació professional (Planas, 1986). En canvi, la LGE va tenir èxit en l'aplicació de la comprensivitat a la franja 10-14 anys, ja que va unificar la primària superior amb el batxillerat elemental (Carabaña, 1997).

Malgrat aquest èxit, desdibuixat pel context sociopolític d'aplicació de la reforma de 1970, una de les grans crítiques que se li va fer va ser precisament la doble titulació en finalitzar l'ensenyament obligatori i la construcció de la doble via professional i acadèmica. La unificació de l'ensenyament secundari esdevé, doncs, una de les reivindicacions més importants dels moviments socials reformistes de finals de la dècada de 1970 i principis de la de 1980, amb l'anomenat "tronc comú». Amb aquesta idea d'unificació del currículum fins als setze anys, es va començar a experimentar la reforma que després quedaria més o menys reflectida a la LOGSE.

Ara que, durant aquesta fase d'experimentació, es va donar un fenomen singular: l'ensenyament comprensiu experimental es va convertir en una tercera via entre el batxillerat i la FP. En un estudi sobre tres centres de formació professional, un dels que havia tingut els tres tipus d'ensenyaments i feia una política d'orientació molt clara, els alumnes de més bon rendiment anaven al batxillerat; els de més mal rendiment, a la FP, i els que no tenien gaires bones notes per optar amb garanties al batxillerat però que no volien «rebaixar-se» $a$ fer formació professional, anaven al "tronc comú», que de comú només en tenia el nom (Merino, 2002). Aquesta pràctica es va estendre per nombrosos centres als anys vuitanta (Álvaro, 1990), i és semblant al que hem vist abans sobre el fracàs de les reformes angleses i alemanyes, ja que tenien centres comprensius de secundària, però al costat de centres tradicionals de batxillerat 0 de preparació a la universitat i centres de formació professional. En definitiva, les reformes comprensives tenen el risc de crear una via més, intermèdia, més que no pas unificar realment el tram de l'ensenyament secundari.

La LOGSE dissenya un sistema comprensiu fins als setze anys i una formació professional integrada com a cicles després de cada etapa educativa: els cicles formatius de grau mitjà (CFGM) després de l'ESO i els cicles formatius de grau superior (CFGS) després del batxillerat. El paral.lelisme amb la LGE (amb el disseny de la llei) és molt gran, amb dues diferències substancials: l'allargament del tronc comú dos anys, dels catorze als setze anys, i l'exigència de la titulació de l'ESO per accedir als CFGM. És coneguda la gran dificultat que ha tingut l'aplicació del segon cicle de l'ESO, amb fortes resistències d'una part important del professorat, sobretot del de batxillerat i també del que s'havia especialitzat en FP2 (Merino, 2002). També hi ha hagut fortes resistències per part de l'alumnat amb un rendiment més bo i per part de les famílies que no veuen gens clars els avantatges de l'ensenyament comprensiu i hi troben molt inconvenients (Merino, 2002), inconvenients adequadament amplificats pels mitjans de comunicació i per la publicació de novel.les o llibres de "pseudoassaig» on s'explica el desastre total que ha comportat l'ESO i la reforma als instituts de secundària. 
Respecte a la FP, hi ha tres fenòmens que poden tornar a refer la doble xarxa acadèmica i professional (Merino, 2002). En primer lloc, l'extensió de les proves d'accés als CFGM com a possibilitat per als alumnes que han suspès l'ESO, que no volen anar a fer un PGS o altres dispositius de formació no reglades. En segon lloc, cada cop més estudiants que han fracassat a primer de batxillerat es matriculen a un CFGM. Com que l'accés a aquesta formació és el títol d'ESO, això vol dir que el professorat té un dilema a l'hora d'avaluar el quart d'ESO, ja que, si no dóna el títol, condemna l'alumne a sortir del sistema educatiu. Però existeix una franja d'estudiants que no tenen les aptituds o les capacitats per fer el batxillerat, però sí per seguir un CFGM, i a aquests estudiants se'ls aprova perquè facin un cicle. Ara bé, aquests estudiants (i sobretot les seves famílies) es troben que legalment es poden matricular al batxillerat i s'hi apunten, i són els que majoritàriament suspenen a primer i es converteixen en un públic potencial per als CFGM. El tercer fenomen que cal destacar és la pressió o demanda dels alumnes que acaben un CFGM per continuar estudiant en un CFGS, ja que no entenen que hagin de seguir el batxillerat per poder-hi accedir. Per fer això tenen dues vies: les proves d'accés als CFGS, si tenen experiència laboral, o un curs de promoció que fa quatre anys que funciona a Catalunya, amb un augment considerable de la matrícula. Tots aquests fenòmens configuren de nou una contrareforma del model comprensiu i integrat de la LOGSE.

Les últimes lleis educatives del govern del PP, partit que no va aprovar la LOGSE quan era a l'oposició, només han sancionat i certificat aquestes tendències, sobretot amb la LOCE, que ha comportat la ruptura de la comprensivitat de l'ESO amb els itineraris a segon cicle ${ }^{15} \mathrm{i}$ la possibilitat d'externalitzar el fracàs als quinze anys (amb els programes d'inserció professional) o fins i tot als catorze (amb grups d'educació «especial»). La Llei de FP i de qualificacions professional apunta, encara que de forma indirecta, a tornar a la segregació de centres de secundària especialitzats en formació professional (això sí, tan reglada com ocupacional i contínua), als quals serà més probable connectar els diferents cicles, tot i que es tracta d'una qüestió encara oberta.

En definitiva, les dificultats d'aplicar reformes comprensives es deriven de les contradiccions internes que tenen i de les resistències dels col-lectius que, objectivament o subjectivament, se senten perjudicats per l'aplicació d'aquestes reformes. A més, el context ideològic no ajuda gaire a justificar polítiques igualitaristes o com a mínim de compensació de desigualtats. L'èmfasi en l'excelllència, la qualitat (encara que es digui per a tothom, no es parla de la mateixa cosa) i la selecció dels millors no són precisament bons companys de viatge de les reformes comprensives.

15. Itineraris que, amb noms diferents, ja es feien a nombrosos instituts a partir dels crèdits variables (Merino, 2002; Garcia, 2001). 


\section{Bibliografia}

Álvaro, M. i altres (1990). Evaluación externa de la Reforma Experimental de las Enseñanzas Medias (II). Madrid: CIDE.

Arum, R.; SHAVIT, Y. (1995). "Secondary Vocational Education and the Transition from School to Work». A: Sociology of Education, vol. 68.

Avis, J. (1992). "Social Difference and Antagonism Within the 16-19 Core Curriculum». British Journal of Sociology of Education, vol. 13, núm. 3.

BALl, S. (1995). Education Reform. A critical and post-structural approach. Buckingham: Open University Press.

BORN, C. (1996). Échec scolaire et système de passage en République Fédérale. Bremen (mimeo).

Boudon, R. (1983). La desigualdad de oportunidades. La movilidad social en las sociedades industriales. Barcelona: Laia.

BOWles, S.; GINTIS, H. (1981). La instrucción escolar en la América capitalista. Madrid: Siglo XXI.

BOWMAN, M.J. (1988). "Links between general and vocational education: does the one enhance the other?». International Review of Education, núm. 34.

CARABAÑA, J. (1997). "La pirámide educativa». A Sociología de las instituciones de educación secundaria. Barcelona: ICE-UB i Horsori (Cuadernos de Formación del Profesorado).

Collins, R. (1989). La sociedad credencialista. Sociología histórica de la educación y la estratificación. Madrid: Akal.

FERnÁNDEZ ENGUITA, M. (1987). «La enseñanza media, encrucijada del sista escolar». A LerenA, C. (ed.). Educación y Sociología en España. Madrid: Akal.

- (1990). Juntos pero no revueltos. Ensayos en torno a la reforma de la educación. Madrid: Visor.

FOURCADE, B. (2000). «Filières académiques et filières professionnelles: Quelle place dans la dynamique des systèmes éducatifs européens?». Conferència de l'Euresco European Societies or European Society. EuroConference on Educational Differenciation in European Societies: causes and consequences. Giens, França, setembre.

GARCIA, M. (2001). L'absentisme escolar en zones socialment desafavorides. El cas de la ciutat de Barcelona. Tesi doctoral (mimeo).

GARCÍA GARRIDO, J.L. (1986). Fundamentos de educación comparada. Madrid: Dydinson.

GrÉGOIRE, R. (1967). L'éducation professionnelle. París: OCDE.

Green, A. (1991). The Reform of Post-16 Education and Training and the Lessons from Europe. Londres: Institute of Education, Universitat de Londres (Working Paper, núm. 11).

Green, A.; Leney, T.; Wolf, A. (2001). Convergencias y divergencias en los sistemas europeos de educación y formación profesional. Barcelona: Pomares.

GrubB, W.N. (1985). "The Convergence of Educational Systems and the Role of Vocationalism». Comparative Education Review, vol. 29, núm. 4.

Gustafsson, A., MADSÉN, T. (1999). "Transition in a School-Based Vocational Training System: The Case of Sweden». A STERN, D.; WAGNER, D. (ed.). International perspectives on the school-to-work transition. New Jersey: Hampton Press, Inc.

Halls, W.D. (1994). «16-19: Some Reflections on Europe and the Reforms». Comparative Education, vol. 30, núm. 1.

HusÉn, T. (1988). Nuevo análisis de la sociedad del aprendizaje. Barcelona: Paidós. 
InUI, A.; Hosogane, T. (1995). Education as a foundation for work? The efficiency and problems of the Japanese upper-secondary school.

JACKSON, N.J. (1999). "Modelling change in a national HE system using the concept of unification». Journal of Education Policy, vol. 14, núm. 4.

KARIYA, T. (1999). «Transition From School to Work and Career Formation of Japanese High School Students». A STERn, D.; Wagner, D. (ed.). International prespectives on the school-to-work transition. New Jersey: Hampton Press, Inc.

KerCKHOFF, A. i altres (1997). «Staying Ahead: The Middle Class and School Reform in England and Wales». Sociology of Education, vol. 70.

LECRERCQ, J.M. (1994). "General Education and Vocational Training at the Postcompulsory Level in Europe: the end of mutual disregard?». Comparative Education, vol. 30, núm. 1.

LlORENT, V.; ORIA, M.R. (1999). La formación profesional en Europa Occidental. Sevilla: Universidad de Sevilla.

Manacorda, M. (1985). «Introducción». A GramsCI, A. La alternativa pedagógica. Barcelona: Hogar del Libro.

MASJUAN, J.M. (1994). El professorat d'ensenyament secundari davant la Reforma. Barcelona: ICE de la UAB.

MCMAHON, W.J. (1988). «The economics of vocational and technical education: do the benefits outweigh the costs?». International Review of Education, núm. 34.

MERINO, R. (2002). De la contrareforma de la formació professional de la LGE a la contrareforma de la LOGSE. Itineraris i cicles de formació professional després de l'ensenyament secundari comprensiu. Tesi doctoral.

MingAT, A.; TAN, J.P. (1988). "The economic returns to investment in projectrelated training: some empirical evidence». International Review of Education, núm. 34.

MÜller, W.; WOLBERS, M. (1999). «Educational attainment of young people in the European Union: cross-country variation of trends over time». A MÜLLER, W. i altres. A comparative Analysis of Transitions from Education to Work in Europe. Mannheim (mimeo).

OSTerlund, R. (1999). "School-to-work Transition in Denmark». A STERN, D.; WAGNER, D. (ed.). International prespectives on the school-to-work transition. New Jersey: Hampton Press, Inc.

PEDRÓ, F; PUIG, I. (1998). Las reformas educativas. Una perspectiva politica y comparada. Barcelona: Paidós.

Planas, J. (1986). "La Formación Profesional en España: evolución y balance». Educación y Sociedad, núm. 5.

PlanAS, J.; TATJER, J.M. (1982). Implicacions i problemes de la reforma de l'ensenyament mitjà. Barcelona: ICE de la UAB.

Postman, N. (2000). Fi de l'educació. Una redefinició del valor de l'escola. Vic: Eumo. RAFFE, D.; SpOURS, K. (1997). The Unification of Post-Compulsory Educatoin: Towards a Conceptual Framework. Londres: Institute of Education, University of London (Working Paper, núm. 2).

ResCalli, G. (1995). Il cambiamento nei sistemi educativi. Processi di riforma e modelli europei a confronto. Florència: La Nuova Italia.

Richardson, W.; SpOurs, K. (1996). 14-19 Education and Training Changes and Challenges. Londres: Institute of Education, University of London (Working Pape núm. 1).

RiESMAN, D. (1981). La muchedumbre solitaria. Barcelona: Paidós. 
SpOuRs, K. (1996a). The Strengths and Weaknesses of GNVAs: Principles of Design. Londres: Institut of Education, University of London (Working Paper, núm. 3).

- (1996b). Post-Compulsory Education and Training: Statistical Trends. Londres: Institute of Education, University of London (Working Paper, núm. 7).

SulTANA, P. (1995). «Education and social transicion: vocationalism, ideology and the problems of development». International Review of Education, núm. 41.

SwEET, R. (1999). "An Overview of School-to-Work Arrangements in Australia». A STERN, D.; WAGNER, D. (ed.). International perspectives on the school-to-work transition. New Jersey: Hampton Press, Inc.

TEDESCO, J.C. (1994). «Tendances atuelles des réformes éducatives». Revue Internationale d'Éducation, núm. 1.

Tessaring, M. (1999). Formación para una sociedad en cambio. Informe acerca de la situación actual de la investigación sobre la formación profesional en Europa. Salònica: CEDEFOP.

Tiana, A. (1998). «Estructura y dilema de la comprensividad». Cuadernos de Pedagogía, núm. 272.

YounG, M. i altres (1995). GNVQs and Unifiying the Post-16 Curriculum. Londres: Institute of Education, University of London (Unified 16+ Curriculum Series, núm. 11).

- (1997). "Unifying academic and vocational learning and the idea of a learning society». Journal of Education Policy, vol. 12, núm. 6.

ZACHARIAH, M. (1988). «Continuity between school curriculum and vocation: manual labour's ineffective role». International Review of Education, núm. 34. 